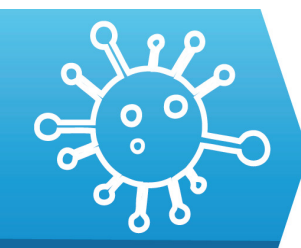

INFECTIOUS DISEASES

\section{Knowledge about the COVID-19 pandemic among undergraduate medical and dental students in Lalitpur, Nepal} Nisha Jha ${ }^{1}$, Neeti Singh ${ }^{2}$, Omi Bajracharya ${ }^{1}$, Tejendra Manandhar ${ }^{1}$,
Pragya Devkota $^{1}$, Sajala Kafle ${ }^{1}$, Pathiyil Ravi Shankar ${ }^{3}$

1) Department of Clinical Pharmacology and Therapeutics, KIST Medical College, Lalitpur, Nepal

2) Department of Community Medicine, KIST Medical College, Lalitpur, Nepal

3) IMU Centre for Education, International Medical University, Kuala Lumpur, Malaysia

DOI: $10.15386 / \mathrm{mpr}-1928$

Manuscript received: 04.10.2020

Received in revised form: 19.12.2020

Accepted: 15.01.2021

Address for correspondence:

nishajha32@gmail.com

This work is licensed under a Creative Commons Attribution-NonCommercialNoDerivatives 4.0 International License

\begin{abstract}
Background. Coronavirus disease-19 (COVID-19) has become a major global problem. There is an urgent need to measure the knowledge of the disease among health science students who can play an active role in pandemic control. The research was conducted to examine COVID-19 knowledge among medical and dental students in a Nepalese medical college, compare the knowledge to other studies in the literature and identify educational needs of students who may be involved in treating COVID-19 patients.
\end{abstract}

Methods. The cross-sectional study was performed during the third week of June among first to final year medical and dental students. As the country was in lockdown, a structured online questionnaire was used. The responses obtained were entered into IBM SPSS Statistics for Windows and the normality of the data checked using onesample Kolmogorov Smirnov test. The demographic parameters were tabulated, and total score compared among different subgroups of participants. The frequency of different measures mentioned by respondents were also noted.

Results. More than half of the participants were females (59.6\%). Nearly half $282(49.8 \%)$ belonged to age group 21-23 years. The majority 415 (73.5\%) were undergraduate medical and $150(26.5 \%)$ were undergraduate dental students. The largest number of respondents, 140 (24.9\%), were from the second year of study and $344(60.9 \%)$ were from urban areas. The median total score was 20 and the interquartile range 4. The maximum possible score was 29. The scores among students belonging to different years of study were significantly different $(\mathrm{p}=0.006)$. Total scores were not significantly different among other subgroups.

Conclusions. The knowledge of the participants was good. Deficiencies in knowledge were noted in certain areas and these should be addressed through an educational intervention. One of the challenges is the rapid evolution of our knowledge about this condition, which may require regular refresher sessions. Similar studies can be undertaken in other medical colleges in the country and in nursing and pharmacy colleges.

Keywords: Coronavirus, COVID-19, dental students, knowledge, medical students, Nepal

\section{Background and aims}

Coronavirus disease-19 (COVID-19) global pandemic has affected many people's health and economic condition and is caused by Severe Acute Respiratory Syndrome Coronavirus 2 (SARS-CoV-2) [1]. The double stranded RNA virus can cause different symptoms and affects various organs like lungs, liver, intestine and neurons [2,3]. Transmission is thought to occur via respiratory droplets from close contact with a person suffering from the disease. The incubation period is between 2 and 14 days and individuals are most contagious when symptoms are worst. Transmission can also occur after contact with asymptomatic people.

Asymptomatic individuals without 
symptoms have the same viral load as the infected patients and may possess similar infectivity [4,5]. Transmission from touching contaminated surfaces and then touching one's face is also suspected though it is not thought to be a common means of spread [6]. The disease is highly contagious, and the main clinical symptoms include malaise, pyrexia, and difficulty in breathing with cough. The disease can lead to several respiratory complications and death if untreated in some cases $[7,8]$.

The public should have adequate knowledge about COVID-19 and its prevention. Information is available on the website of Ministry of Health and Population Nepal about the causative factor, the signs and symptoms and the preventive measures. Information about physical distancing, regular hand washing, and respiratory etiquette are regularly provided through radio and television. Information is also disseminated via mobile phones by the national telecommunication providers to spread awareness about the disease.

Medical and dental students can also be a part of treatment and increase the efficiency of inadequately staffed clinics by taking patient histories, providing patients with laboratory test results, educating patients, documenting visits, and answering questions about COVID-19 [9]. Patients with chronic diseases also need routine care. Pregnant women need routine checkups. Medical students can provide care to the patients who are not suffering from COVID-19 reducing the burden on house officers and junior doctors. Hence, senior medical students can maximize the availability of other clinicians to treat patients with COVID-19 [10]. Dental care also needs to be provided during the pandemic.

Medical Schools Council (MSC) of the United Kingdom and the Association of American Medical Colleges (AAMC) of the United States have published guidelines regarding the participation of medical students in providing healthcare during the pandemic $[11,12]$. Medical students can work as volunteers with adequate training and take part in managing the pandemic within their competencies under the supervision of seniors with adequate personal protective equipment (PPE) [12]. Many medical students have taken part in efforts towards managing this pandemic [13]. Medical students from the medical schools in United States, Italy and United Kingdom had graduated early, so that they can serve as physicians during this pandemic [10].

As COVID-19 cases are still present more than twelve months into the pandemic, and newer more infectious variants are regularly reported, it may be better to involve the medical and dental students in Nepal. These are future doctors of the country. They can also play an important role in supporting vaccination efforts. They are the educated members of the community and will be an important taskforce towards managing COVID-19.

In Nepal, both the undergraduate medical and dental programs are of four and half years' duration followed by a year of rotating internship. Students join the Bachelor of Medicine and Bachelor of Surgery (MBBS) and Bachelor of Dental Surgery (BDS) programs after completing twelve years of schooling $[14,15]$. Medical and dental students can be provided online training on infectious disease epidemiology, infectious disease control and outbreak response with special reference to COVID-19. Therefore, to facilitate outbreak management and design educational programs, there is an urgent need to understand the existing knowledge of COVID-19 among these students.

Therefore, this study was undertaken to obtain information about knowledge of coronavirus disease among medical and dental students in a Nepalese medical college, compare the knowledge to that in the literature, and study the educational needs of these students who may be called in to support the treatment and vaccination efforts of COVID-19 in Nepal.

\section{Methods}

\section{Study design}

A cross-sectional survey was designed assessing the medical and dental students' knowledge, regarding the COVID-19 pandemic.

\section{Study duration}

The data were collected during $20^{\text {th }}$ June to $26^{\text {th }}$ June 2020, when the country was under lockdown due to COVID-19.

\section{Sample selection}

Students from first year to final year MBBS and BDS were selected for the study. Written consent was obtained online from the participants.

\section{Sample size}

The institution has a total of 506 medical students excluding interns and a total of 162 dental students making a total of 668 students. All students were approached for this study.

\section{Sampling method and technique}

All students willing to participate were included after obtaining written informed consent.

\section{Inclusion and exclusion criteria}

All students from first year to final year MBBS and BDS from the institution. Any student unwilling to respond to the survey was excluded. Interns and alumni were excluded.

\section{Study questionnaire}

The study questionnaire was designed by the researchers based on the literature and referring to World Health Organization (WHO) guidelines on COVID-19 [16]. The questionnaire had three sections. Section I obtained the written consent online. Section II contained demographic details for age, gender, year of study, study stream and area of residence. Section III contained questions regarding knowledge of COVID-19 among the students. There were questions to assess the knowledge about clinical symptoms, routes of transmission, use of medicines and about prevention and control of COVID-19 using face masks, sanitizers, and quarantine measures. 
Twenty questions were single best response multiple choice questions having 5 distractors. One question was an opinion poll regarding the best method to control COVID-19. Ten questions were of true/false type. Correct answers were scored as ' 1 ' and incorrect answers as ' 0 '. Same scoring system was followed for all the multiple-choice questions and Yes/No types of questions. Similar type of scoring was used in another study from Turkey done among nursing students [17]. The survey instrument developed was also similar to that used in studies from Jordan and India, which had 26 questions related to the demographics and about the quarantine period, the disease itself and also about the disease transmission routes, clinical features, recovery rates and the use of medicines etc $[18,19]$.

\section{Pretesting of the questionnaire}

The questionnaire was validated for content by the researchers and by experts of General medicine department. The validity was also assessed by pilot testing the questionnaire by administering to sixty students (alumni) who had already passed the MBBS course. The reliability was assessed by calculating the Cronbach alpha. The data from pilot testing was not included in the final analysis. The value of Cronbach alpha was 0.7 .

\section{Data collection methods}

Since the study was conducted during lockdown it was not possible to collect the responses directly from the students, hence a structured online questionnaire was used as a data collection tool. The online questionnaire was sent to the participants via their e-mail and social networking accounts. Class representatives of each year were contacted. Similar method was used in another study, where class representatives were also involved in forwarding and sharing the questionnaire link to their friends [20].

Students completed the questionnaire at leisure within the period of the study. They signed an integrity pledge that they will answer the questions by themselves and would not consult other resources and with their friends and family members while answering the same.

\section{Data analysis}

The responses obtained from the questionnaire were entered in IBM SPSS Statistics for Windows, Version 26 and the normality of the data checked using one-sample Kolmogorov Smirnov test. The total score was calculated by adding the scores of all the questions except question 25 which was asking participant's opinions. Each correct answer was given a score of 1 and the maximum possible score was 29. The total score and the individual scores were noted not to follow a normal distribution and median scores were calculated. Comparisons of total scores among different subgroups of students was performed using appropriate non-parametric tests $(p<0.05)$. The demographic parameters were analyzed descriptively and tabulated as number and percentage.

Ethics approval and consent to participate

The research proposal was approved by the
Institutional Review Committee (IRC) of the Medical College with reference number 2076/77/39. The participants were informed about the purpose of the research and written consent obtained prior to enrolling them. Anonymity was maintained throughout the research and no information related to individual respondents are available in the public domain.

\section{Results}

Out of the six hundred and sixty-eight students, five hundred and sixty-five $(84.6 \%)$ participated. The demographic characteristics including age, gender, stream of study, year of study and area of residence has been presented in table I.

More than half of the participants were females. Out of the 565 participants, 336 (59.6\%) were females and 229 (40.4\%) males. Nearly half of the participants, 282 (49.8\%) belonged to the age group 21-23 years. Majority of the participants, $415(73.5 \%)$ were from MBBS stream and $150(26.5 \%)$ students were from BDS stream. The largest number of respondents, $140(24.9 \%)$ were from second year of study and $344(60.9 \%)$ were from urban areas.

Table I. Demographic characteristics of respondents $(n=565)$.

\begin{tabular}{l|c}
\hline Characteristic & Number (percentage) \\
\hline Age (in years) & $53(9.4)$ \\
$17-20$ & $282(49.8)$ \\
$21-23$ & $223(39.4)$ \\
$23-26$ & $7(1.2)$ \\
26 years and above & \\
Gender & $229(40.4)$ \\
Male & $336(59.6)$ \\
Female & \\
Education & $415(73.5)$ \\
MBBS & $150(26.5)$ \\
BDS & \\
Year of Study & $100(17.9)$ \\
First Year & $140(24.9)$ \\
Second Year & $127(22.7)$ \\
Third Year & $112(19.9)$ \\
Fourth Year & $86(15.2)$ \\
Final Year & \\
Area of residence & $72(12.7)$ \\
Rural & $344(60.9)$ \\
Urban & $149(26.4)$ \\
Semi urban &
\end{tabular}

The median total score was 20 and the interquartile range was 4 . The maximum possible score was 29 . The median scores among different subgroups of respondents is shown in table II along with the interquartile range and the $\mathrm{P}$ values. The scores among students of different years of study were significantly different $(\mathrm{p}=0.006)$. The median total scores were significantly different among second- and fourth-year students. 
The areas having good level of knowledge $(>70 \%)$ among the students were about the causative factor of the disease, the nature of the virus, common symptoms of COVID-19, concentration of alcohol in sanitizers, transmission routes, method of hand hygiene, self-isolation period, effective mask type used for prevention, and effective measure for protecting oneself and vulnerable individuals having comorbidities from COVID-19. Similarly, the knowledge scores for the true/false questions dealing with the similarity between SARS and MERS causative factors, non-availability of specific drugs for treating corona infections, use of antibiotics in COVID-19, use of Remdesivir, use of convalescent plasma therapy, risk of infection transmission and use of homeopathic medicine arsenicum album $30 \mathrm{C}$ in preventing corona infection was found to be good.

The areas where the students had less knowledge scores were about isolation period for COVID-19 patients as recommended by $\mathrm{WHO}$, the type of personal protective equipment (PPE) recommended for Physician/Staff running fever/screening clinics, estimated proportion of people who recovered without need of hospital stay, meaning of "Self-isolate" in COVID-19 infection, recommended test for early case detection of COVID-19, use of thermal scanners, the $\mathrm{R}$ number and the distance required to maintain social distancing according to WHO. Similarly, the knowledge for responses from true/false type of questions about COVID-19 treatment guidelines developed for healthcare professionals working at hospitals in Nepal, use of betahistine in COVID-19 were also found to be low.

Figure 1 shows strategies suggested by students for managing the COVID-19 pandemic.

The most common response was sealing international borders as the human movement will be reduced and the risk of community transmission minimized. Second was increasing laboratory and diagnostic facilities as these may help to diagnose the cases early and can reduce the risk of transmission. Similar responses were obtained about increasing hospital facilities which can help in treating the infected COVID-19 patients. Community mitigation came as fourth followed by drafting legislation for control. Community mitigation is done for reducing the rate of infection transmission from person to person contact and includes the social distancing measures.

Table II. Median scores among different subgroups of respondents.

\begin{tabular}{l|c|c} 
Characteristic & $\begin{array}{c}\text { Median score } \\
\text { (Inter quartile range) }\end{array}$ & P value \\
\hline Age (in years) & $20(4)$ & \\
$17-20$ & $20(3)$ & 0.091 \\
$21-23$ & $20(4)$ & \\
$23-26$ & $21(7)$ & \\
26 years and above & & \\
Gender & $20(4)$ & \\
Male & $20(4)$ & \\
Female & & \\
Education & $20(4)$ & \\
MBBS & $20(3)$ & \\
BDS & & \\
Year of Study & $20(4)$ & \\
First Year & $20(3)$ & \\
Second Year & $19(3)$ & \\
Third Year & $20(3)$ & \\
Fourth Year & $20(3)$ & \\
Final Year & & \\
Area of residence & $20(4)$ & \\
Rural & $20(4)$ & \\
Urban & $20(4)$ & \\
Semi urban & &
\end{tabular}

The number of respondents providing correct responses to individual questions is mentioned in tables III and IV. Table III presents the multiple-choice questions while table IV is concerned with true-false questions.

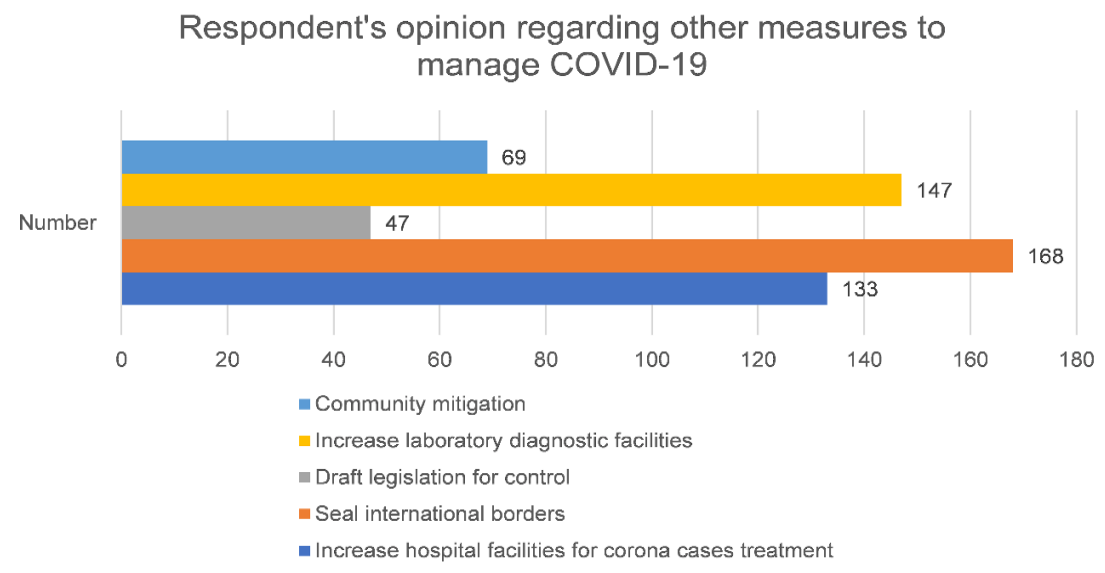

Figure 1. Responses suggested by the participants for the management of corona virus disease-19 (COVID-19) other than those provided by the authors in the questionnaire. 
Table III. Number and percentage of students providing correct answers to multiple choice questions.

\begin{tabular}{|c|c|c|}
\hline Q. No & Statement (Correct answer) & $\begin{array}{l}\text { Number and \% of } \\
\text { respondents answering } \\
\text { correctly }(\mathrm{n}=\mathbf{5 6 5})\end{array}$ \\
\hline 1. & The virus causing COVID-19 infection is called as: [SARS-CoV-2] & $540(95.6)$ \\
\hline 2. & Corona virus is a: [Single stranded RNA virus] & $524(92.7)$ \\
\hline 3. & $\begin{array}{l}\text { The most common set of symptoms of COVID-19 are: } \\
\text { [Fever, Dry Cough and Tiredness] }\end{array}$ & $443(78.4)$ \\
\hline 4. & The minimum concentration of alcohol in hand sanitizers to kill the virus should be: $[70 \%]$ & $399(70.6)$ \\
\hline 5. & $\begin{array}{l}\text { According to current evidence, the "commonest" mode of transmission of COVID-19 infection is: } \\
\text { [Respiratory droplets] }\end{array}$ & $400(71)$ \\
\hline 6. & $\begin{array}{l}\text { Preferred method of hand hygiene to reduce COVID-19 transmission is: } \\
\text { [Hand rub with soap and water for } 20 \text { secs] }\end{array}$ & $467(82.7)$ \\
\hline 7. & WHO recommended self-isolation period for COVID-19 is: [14 Days] & $517(91.5)$ \\
\hline 8. & $\begin{array}{l}\text { Which of the following is recommended by the WHO for isolation of a patient with confirmed } \\
\text { case of COVID-19 infection? } \\
\text { [Airborne infection isolation room with exhaust] }\end{array}$ & $198(35)$ \\
\hline 9. & $\begin{array}{l}\text { In Nepal, for Physician/Staff running the fever/screening clinics the PPEs recommended does not } \\
\text { include: [Respirator N95] }\end{array}$ & $155(27.4)$ \\
\hline 10. & Most effective mask for preventing corona infection would be: [N-95 face mask] & $533(94.3)$ \\
\hline 11. & $\begin{array}{l}\text { In COVID-19 infection, an estimated proportion of people who recovered without need of hospital } \\
\text { stay are: }[80 \%]\end{array}$ & $175(31)$ \\
\hline 12. & $\begin{array}{l}\text { "Self -isolate" in COVID-19 infection means: [Persons with COVID-19 symptoms stays at home } \\
\text { and does not go to work, school or public places] }\end{array}$ & $203(35.9)$ \\
\hline 13. & Recommended test for early case detection of COVID-19 infection is: [Molecular test (PCR)] & $201(35.6)$ \\
\hline 14. & Thermal scanners are used to detect raised temperature from: [Any infection] & $328(58.1)$ \\
\hline 15. & Live COVID-19 map is used to: [Update estimate of geographic spread by country] & $324(57.3)$ \\
\hline 16. & $\begin{array}{l}\text { An important measure for protecting oneself from COVID-19 is: } \\
\text { [Regular hand hygiene and avoiding crowded places] }\end{array}$ & $561(99.3)$ \\
\hline 17. & $\begin{array}{l}\text { Which of the following individuals has the highest risk of mortality from COVID-19? } \\
\text { [An } 80 \text {-year-old suffering from diabetes and hypertension] }\end{array}$ & $539(95.4)$ \\
\hline 18. & $\begin{array}{l}\text { The R number refers to: } \\
\text { [The average number of people who can be infected by one infected person] }\end{array}$ & $378(66.9)$ \\
\hline 19. & $\begin{array}{l}\text { How much distance should two persons be apart to maintain social distancing according } \\
\text { to WHO? [ } 3 \text { feet] }\end{array}$ & $233(41.2)$ \\
\hline
\end{tabular}

Table IV. Number and percentage of respondents providing correct answers to true or false questions.

\begin{tabular}{|c|c|c|}
\hline Q. No & Statement (Correct answer) & $\begin{array}{l}\text { Number and } \% \text { of } \\
\text { respondents providing } \\
\text { the correct response }\end{array}$ \\
\hline 1. & $\begin{array}{l}\text { Middle East Respiratory Syndrome (MERS) and Severe Acute Respiratory Syndrome (SARS) are } \\
\text { caused by similar viral species as COVID-19. [True] }\end{array}$ & $449(79.5)$ \\
\hline 2. & $\begin{array}{l}\text { COVID- } 19 \text { treatment guidelines have been developed for healthcare professionals working at } \\
\text { hospitals in Nepal. } \\
\text { [True] }\end{array}$ & $175(31)$ \\
\hline 3. & There are specific drugs available to treat corona virus infection. [No] & $521(92.2)$ \\
\hline 4. & Antibiotics can cure corona virus infection. [False] & $437(77.3)$ \\
\hline 5. & Convalescent plasma therapy can be used in treating corona infections. [Yes] & $397(70.3)$ \\
\hline 6. & Betahistine shows promise in treating corona virus infection. [No] & $68(12)$ \\
\hline 7. & Remdesivir is a new antiviral drug still in clinical trials for corona virus treatment. [Yes] & $495(87.6)$ \\
\hline 8. & $\begin{array}{l}\text { Ibuprofen is recommended as an anti-inflammatory agent in COVID-19. [No] } \\
\text { At the time the study was conducted this was correct and concerns were raised about the use of } \\
\text { NSAIDs in COVID-19. Later a large study in Denmark showed that NSAIDs do not lead to more } \\
\text { severe disease. }\end{array}$ & $203(35.9)$ \\
\hline 9. & Can COVID-19 be transmitted from a person who has no symptoms? [Yes] & $536(94.9)$ \\
\hline 10. & The homeopathic medicine Arsenicum album 30C can effectively prevent COVID-19. [No] & $512(90.6)$ \\
\hline
\end{tabular}




\section{Discussion}

COVID-19 pandemic has severely impacted individuals and health care workers throughout the world. At the end of June 2020, cases were slowly decreasing in countries where there was early outbreak of the pandemic, while in Nepal the number of cases started to rise rapidly. In early December 2020 the number of cases continued to rise and there have been second and third pandemic waves in many countries. Vaccines against the diseases have now begun to be administered in many countries. Vaccination was started in Nepal for health workers and other front liners in January 2021 and the number of cases is now declining. This study was conducted to ascertain the status of students' knowledge about the COVID-19 pandemic in June 2020. Most students had good knowledge about the corona virus disease. Students from MBBS and BDS stream were aware of the causative factors for the COVID-19 disease (95.6\%) and the type of virus causing this infection $(92.7 \%)$. This was in accordance with a recent study from Turkey and Pakistan [17,21], where most students $(97.4 \%)$ were aware of the causes and the viral nature of the disease. A study from India and Saudi Arabia also showed that 92.7\%, and $94.7 \%$ of the participants had good knowledge about the disease $[22,23]$.

Our study showed that only $71 \%$ of students were aware about the mode of transmission of this virus, which is lesser compared to similar studies from India and Saudi Arabia among students, where $91 \%$ and $98.1 \%$ of students knew about the transmission modes and the signs and symptoms of the disease [22,23]. A study from Jordan evaluated the knowledge of transmissions of infection from one infected individual to others [19]. Our study did not have such type of question. With the passage of time more information is known about COVID-19 and the information is more widely disseminated. In the present study $78.4 \%$ of participants knew about the signs and symptoms of COVID-19, which is lesser compared to a study from India, in which $86.7 \%$ of participants were aware of these symptoms, and from Uganda, where $95 \%$ of students were aware of it $[22,24]$. In the present study $99.3 \%$ of participants were aware of the important protective measures like avoiding crowds and maintaining hand hygiene. This is also in accordance with the studies from India, where $96.9 \%$ and $98.61 \%$ of participants knew about preventive measures $[24,26]$. Similar observations were seen for the recommended 14 days of isolation period for the affected patients [25].

In this study, medical and dental students had acceptable (70\% of maximum) knowledge about coronavirus. Good knowledge about the causative factors, the virus, and the routes of transmission can be attributed to the availability of information in the electronic media such as television, radio, social networking sites, and different websites. These findings were also seen in a study done among university students in Jordan and
Saudi Arabia [20,23,27].

Studies have shown that availability of information in mass and social media can be a source of information for the students $[22,23]$. Of the respondents, $91.5 \%$ were also aware of the cautionary actions, self-isolation period as per WHO guidelines and the effective use of mask for preventing corona infection (94.3\%). These results were like those from other published studies [25,28,29]. The knowledge levels regarding these questions were high in our study as compared to another study, where the knowledge for social distancing and wearing a mask was found to be $62.64 \%$ and the same for hand sanitization was $66.42 \%$ [30].

The results showed that for the questions regarding self-isolation in COVID-19 infection and recommended test for early case detection, a smaller number of participants responded correctly. The correct responses were only from $35 \%$ of participants. Similarly, for the statements for WHO recommendation for isolation of a patient with confirmed case of COVID-19 infection, only 35\% of participants responded correctly. Results were better for the statements regarding thermal scanners; $58.1 \%$ of participants responded that these were used to detect raised temperature from any infection. Social distancing issues were responded correctly by only $41.2 \%$ of students.

The knowledge levels among interns and graduated students were higher as compared to the students who are studying in other years according to a study from Iran [31]. The scores for the medical and dental students were significantly different according to years of study $(\mathrm{p}=0.033)$. Median score was significantly higher among those in the higher years of study. This may be due to content and curricula during the years of study created better understanding about diseases [32].

There was no difference in total score among BDS and MBBS students ( $\mathrm{P}$ value $=0.732$ ). This may be due to access to various sources of information including government health authorities and social media which plays pivotal role in knowledge gain [33]. This finding was different to findings from Saudi Arabia where students from MBBS background were found to be more aware (96.1\%) than the students from BDS background (86.2\%) [23]. Similar findings were indicated in a study where older students in a higher year of study showed better knowledge as compared to the younger students from initial years of medical education $[18,26]$.

Regarding the treatment of corona virus by antibiotics, our study has shown that $77.3 \%$ of participants responded correctly, which is less compared to a similar study from Jordan and Italy, where $88.6 \%$ and $80.7 \%$ of participants responded correctly $[18,33]$. Similarly, the responses for a question regarding the specific drugs available for treating corona virus, in our study correct responses were obtained from $92.2 \%$ of respondents, which was better than the Italian study, where the correct responses were only $69.7 \%$ [34]. 
The median knowledge score in our study was $72.4 \%$ (21 out of 29). The study conducted in Debre Birhan University, Ethiopia showed that the knowledge score was $73.8 \%$ [35], while it was $88.2 \%$ in a multicenter study from Ethiopia [36]. The knowledge score depends on several parameters including the respondents and the questions used to assess knowledge and understanding. Another study from Jordan showed a high knowledge of more than $80 \%$ and a Turkish study revealed a higher knowledge levels in female midwifery students compared to the present one $[17,18]$.

The areas where the participants were having lesser knowledge were on PPE and facilities for proper management of COVID-19 at health facilities. In today's circumstances when there is high demand of PPEs, health science students must have correct knowledge on types of PPEs recommended at various workstations at health facilities [34]. Also, only $31 \%$ of respondents were aware that COVID-19 treatment guidelines have been developed for healthcare professionals working at hospitals in Nepal [37]. These are the areas where educational interventions can be targeted for better level of knowledge and to fill in the gaps of knowledge related to COVID-19. Thus, student knowledge in our study is lower compared to that noted in other studies in the literature as mentioned. Some of the questions used in our study were similar, while others were different from previous studies. The overall knowledge score was above $70 \%$ of the total.

Universities and medical colleges also share information about COVID-19 with students for better understanding of the disease along with its preventive measures. The students have not yet been placed in clinical settings for volunteering to help with the pandemic. An informal survey was done prior to conducting online learning at the institution to assess the availability of stable internet and the devices needed such as smart phones, laptops, and desktops. Majority of the students had the access needed for successful conduct of online learning. Very few students (less than 2\%) were not able to attend online learning due to slow internet speed. The institution is situated in the Kathmandu valley and most students are from within the valley and other urban centers. Medical and dental colleges in the country have shifted to online learning according to the authors' informal discussions with educators in other institutions.

Universities in Nepal had instructed affiliated medical colleges to conduct online teaching and learning to reduce any delays and disturbances in academics due to the pandemic [38]. Various online software was used for initiating online teaching and learning sessions by the faculty members. This process was full of challenges for both the educators and the learners especially considering the unstable internet and less knowledge in the area of digital learning [39].

The knowledge gap mentioned above should be addressed through designing an educational intervention. Regular education programs covering areas where student knowledge was lower can be considered. The education process can be made more interesting through activities and group work. The major problems were noted in practical clinical and prevention and control aspects of COVID-19. A short module about these aspects of the pandemic can be offered by the departments of Community medicine and General medicine. Online videos and other resources are available for some diagnostic and treatment procedures and these can be incorporated into the module. The knowledge gaps can be addressed by preparing the guidelines and standard operating procedures with a clear detail towards the roles of medical and dental students in managing such pandemics [39].

Dental students face the risk of airborne and respiratory droplet borne infections during dental procedures and this should be properly addressed during the course [26,40]. Students may not have a secure and private space for participating in digital learning due to the presence of family members due to the lockdown. Online learning can be considered as half a loaf of bread is better than nothing especially in the Nepalese context [38]. A recent article mentions about the challenges of online learning in low- and middle-income countries [41]. Most are applicable in the Nepalese context also. Online learning has not been used much previously in the institution. Online resources and an online library are absent. A learning management system is also not available. The institution has not conducted any assessments online. A situation like ours we believe may be prevalent in many medical and dental schools in developing countries. Medical and dental students can be a useful addition to the health manpower (with an emphasis on keeping them safe and only carrying out tasks under supervision and within their abilities). A similar study could be conducted in other institutions in developing nations to identify possible knowledge gaps and develop learning programs to address these.

Strength and limitations: Good response rate was the strength of the study. The study also had limitations. Student knowledge was tested only by using a questionnaire and the information was not triangulated with that obtained from other sources. The study was cross-sectional and was conducted only in a single institution. Despite the integrity pledge we cannot rule out that students did not consult other information sources or their friends and family members while answering the questionnaire.

The information about the pandemic is rapidly changing. The correct answers were current in June 2020 when the study was conducted. The rapid evolution of knowledge regarding the pandemic and the need to constantly update our knowledge can be considered as a limitation here. We have highlighted this for the use of NSAIDs in COVID. The recommended period of quarantine has been shortened in many countries and the 
status of Remdesivir is not very clear. Hence frequent sessions may be needed for students as knowledge about the pandemic changes.

\section{Conclusion}

Our study shows that there is good knowledge about COVID 19 among medical and dental students. More than $90 \%$ of the respondents had correct knowledge about causative agent and strain, effective mask for corona virus protection, self-isolation period, effective preventive measures like avoiding crowd and frequent hand washing. Surprisingly, only $71 \%$ on respondents correctly stated that respiratory droplet is the source of infection for COVID-19. This knowledge gap among 29\% respondents is very crucial for medical and dental students as they are focal persons to work with the community and share their knowledge correctly with them.

In countries where epidemic is on the rise, strategies to keep health science students updated with proper information related to COVID-19 is important. The lacunae noted can be addressed through educational sessions. As the knowledge about the disease is being constantly updated frequent refresher sessions may be required. Similar studies can be undertaken in other medical colleges in the country and in nursing and pharmacy colleges also. This can identify the level of knowledge among health science students in the country and help plan educational sessions.

\section{References}

1. Lai CC, Shih TP, Ko WC, Tang HJ, Hsueh PR. Severe acute respiratory syndrome coronavirus 2 (SARS-CoV-2) and coronavirus disease-2019 (COVID-19): The epidemic and the challenges. Int J Antimicrob Agents. 2020;55:105924.

2. Weiss SR, Leibowitz JL. Coronavirus pathogenesis. Adv Virus Res. 2011;81:85-164.

3. Masters PS, Perlman S. Coronaviridae. In: Knipe DM, Howley PM, eds. Fields virology. $6^{\text {th }}$ ed. Lippincott Williams \& Wilkins, 2013, p. 825-858.

4. Chen Y, Wang AH, Yi B, Ding KQ, Wang HB, Wang JM, et al. Epidemiological characteristics of infection in COVID-19 close contacts in Ningbo city. Zhonghua Liu Xing Bing Xue Za Zhi. 2020;41:667-671.

5. Zou L, Ruan F, Huang M, Liang L, Huang H, Hong Z, et al. SARS-CoV-2 viral load in upper respiratory specimens of infected patients. N Engl J Med. 2020;382:1177-1179.

6. Centers for Disease Control and Prevention. 2019 novel coronavirus. Available from: http://www.cdc.gov/ coronavirus/2019-ncov/index.html

7. Epidemiology Working Group for NCIP Epidemic Response, Chinese Center for Disease Control and Prevention. The Novel Coronavirus Pneumonia Emergency Response Epidemiology Team. The epidemiological characteristics of an outbreak of 2019 novel coronavirus diseases (COVID-19) in China. Zhonghua Liu Xing Bing Xue Za Zhi. 2020;41:145-151.
8. Chen N, Zhou M, Dong X, Qu J, Gong F, Han Y, et al. Epidemiological and clinical characteristics of 99 cases of 2019 novel coronavirus pneumonia in Wuhan, China: a descriptive study. Lancet. 2020;395:507-513.

9. Krieger P, Goodnough A. Medical students, sidelined for now, find new ways to fight coronavirus. The New York Times. 23 March 2020. Available from: https://www.nytimes. com/2020/03/23/health/medical-students-coronavirus.html

10. Miller DG, Pierson L, Doernberg S. The Role of Medical Students During the COVID-19 Pandemic. Ann Intern Med. 2020;173:145-146.

11. Medical Schools Council of United Kingdom. Statement of expectation. Medical Student Volunteers in the NHS. Available from: https://www.medschools.ac.uk/media/2622/ statement-of-expectation-medical-student-volunteers-inthe-nhs.pdf

12. Whelan A, Prescott J, Young G, Caranese MV, Mckinney R. Guidance on medical students' participation in direct patient contact activities: principles and guidelines. Association of American Medical Colleges. Available from: https://www. aamc.org/system/files/2020-04/meded-April-14-Guidanceon-Medical-Students-Participation-in-Direct-PatientContact-Activities.pdf

13. Gallagher TH, Schleyer AM. "We Signed Up for This!" Student and Trainee Responses to the Covid-19 Pandemic. N Engl J Med. 2020;382:e96.

14. Shankar PR. Undergraduate medical education in Nepal: one size fits all? J Educ Eval Health Prof. 2011;8:9.

15. Medical Education Department Tribhuvan University. Curriculum for bachelor of medicine and bachelor of surgery (MBBS) 2008. Available from: https://digitalmedicine. com.np/tribhuvan-university-tu-curriculum-for-mbbscc70dae71f3

16. World Health Organization. Rolling updates on coronavirus disease (COVID-19). Vol 2020. Available from: https://www. who.int/emergencies/diseases/novel-coronavirus-2019/ events-as-they-happen

17. Sögüt S, Dolu İ, Cangöl E. The relationship between COVID-19 knowledge levels and anxiety states of midwifery students during the outbreak: A cross-sectional web-based survey [ahead of print, 2020 Jun 14]. Perspect Psychiatr Care. 2020;10.1111/ppc. 12555.

18. Sallam M, Dababseh D, Yaseen A, Al-Haidar A, Ababneh NA, Bakri FG, et al. Conspiracy beliefs are associated with lower knowledge and higher anxiety levels regarding COVID-19 among students at the University of Jordan. Int J Environ Res Public Health. 2020:17;4915.

19. Modi PD, Nair G, Uppe A, Modi J, Tuppekar B, Gharpure AS, et al. COVID-19 Awareness Among Healthcare Students and Professionals in Mumbai Metropolitan Region: A Questionnaire-Based Survey. Cureus. 2020;12:e7514. doi:10.7759/cureus. 7514

20. Khasawneh AI, Humeidan AA, Alsulaiman JW, Bloukh S, Ramadan M, Al-Shatanawi TN, et al. Medical Students and COVID-19: Knowledge, Attitudes, and Precautionary Measures. A Descriptive Study from Jordan. Front Public Health. 2020;8:253.

21. Ikhlaq A, Bint-E-Riaz H, Bashir I, Ijaz F. Awareness and 
Attitude of Undergraduate Medical Students towards 2019-novel Corona virus. Pak J Med Sci. 2020;36(COVID19S4):S32-S36.

22. Maheshwari S, Gupta PK, Sinha R, Rawat P. Knowledge, attitude, and practice towards coronavirus disease 2019 (COVID-19) among medical students: A cross-sectional study. J Acute Dis. 2020;9:100-104.

23. Saleem M, Alenazi F, Moursi SA, Ahmed HG, Alam MJ, Alzapni MIA, et al. Evaluation of Knowledge and Awareness regarding COVID-19 Disease among Medical and Dental students in Saudi Arabia. Indian J Comm Health. 2020;32:486-492.

24. Olum R, Kajjimu J, Kanyike AM, Chekwech G, Wekha G, Nassozi DR, et al. Perspective of Medical Students on the COVID-19 Pandemic: Survey of Nine Medical Schools in Uganda. JMIR Public Health Surveill. 2020;6:e19847.

25. Asaad A, El-Sokkary R, Alzamanan M, El-Shafei M. Knowledge and attitudes towards Middle East respiratory syndrome-coronavirus (MERS-CoV) among health care workers in south-western Saudi Arabia. East Mediterr Health J. 2020;26:435-442.

26. Ramesh M, Krishnan R, Jaganathan S. Evaluation of Knowledge, Psychological, Social and Economic Aspects of Covid-19 Pandemic among Dental Professionals- A Crosssectional Study. J Clin Diagn Res. 2020;14:ZC09-ZC15

27. Peng Y, Pei C, Zheng Y, Wang J, Zhang K, Zhenj K, et al. A cross-sectional survey of knowledge, attitude and practice associated with COVID-19 among undergraduate students in China. BMC Public Health. 2020;20:1292.

28. Shekarappa H, Guttal K, Iyer V, Gupta V, Shetty P. Knowledge, attitude and preventive practices related to novel Coronavirus Infection (COVID-19) among patients attending dental hospital in Dharwad. Asian J Med Sci. 2020;11:1-7.

29. Al-Mohaissen M. Awareness among a Saudi Arabian university community of Middle East respiratory syndrome coronavirus following an outbreak. East Mediterr Health J. 2017;23:351-360.

30. Baloran ET. Knowledge, attitudes, anxiety, and coping strategies of students during COVID-19 pandemic. Journal of Loss and Trauma. 2020;25:635-642. doi: $10.1080 / 15325024.2020 .1769300$
31. Taghrir MH, Borazjani R, Shiraly R. COVID-19 and Iranian Medical Students; A Survey on Their Related-Knowledge, Preventive Behaviors and Risk Perception. Arch Iran Med. 2020;23:249-254.

32. Gurpinar E, Musal B, Aksakoglu G, Ucku R. Comparison of knowledge scores of medical students in problem-based learning and traditional curriculum on public health topics. BMC Med Educ. 2005;5:7.

33. Bhagavathula AS, Aldhaleei WA, Rahmani J, Mahabadi MA, Bandari DK. Knowledge and Perceptions of COVID-19 Among Health Care Workers: Cross-Sectional Study. JMIR Public Health Surveill. 2020;6:e19160.

34. Khan MU, Shah S, Ahmad A, Fatokun O. Knowledge and attitude of healthcare workers about Middle East Respiratory Syndrome in multispecialty hospitals of Qassim, Saudi Arabia. BMC Public Health. 2014;14:1281.

35. Nour MO, Babilghith AO, Natto HA, Al-Amin FO, Alawneh SM. Knowledge, attitude and practices of healthcare providers towards MERS-CoV infection at Makkah hospitals, KSA. Int Res J Med Med Sci. 2015;3:103-112.

36. Gallè, F, Sabella EA, Molin G, De Giglio O, Caggiano G, Di Onofrio V, et al. Understanding Knowledge and Behaviors Related to CoViD-19 Epidemic in Italian Undergraduate Students: The EPICO Study. Int J Environ Res Public Health. 2020;17:3481.

37. Implementation guide. CD4 knowledge. Meeting demand for PPE, hospital beds and other equipment. 2020. Available from: https://www.c40knowledgehub.org/s/article/Citiesapproaches-to-meeting-demand-for-PPE-hospital-beds-andother-equipment?language $=$ en_US

38. Atreya A, Acharya J. Distant virtual medical education during COVID-19: Half a loaf of bread. Clin Teach. 2020;17:418419.

39. Guragai M. Nepalese Medical Students in the COVID-19 Pandemic: Ways Forward. JNMA J Nepal Med Assoc. 2020;58:352-354.

40. Ghai S. Are dental schools adequately preparing dental students to face outbreaks of infectious diseases such as COVID-19? J Dent Educ. 2020;84:631-633.

41. Cecilio-Fernandes D, Parisi M, Santos T, Sandars J. The COVID-19 pandemic and the challenge of using technology for medical education in low and middle income countries. MedEdPublish 2020:9:74. 